\title{
EFFICIENCY AND PRODUCTIVITY CHANGE IN THE ENGLISH HIGHER EDUCATION SECTOR FROM 1996/97 TO 2004/5*
}

\author{
by \\ JILL JOHNES \\ Lancaster University Management School, Lancaster University
}

\begin{abstract}
In this study we use a distance function approach to derive Malmquist productivity indexes for 112 English higher education institutions (HEIs) over the period 1996/97 to 2004/5. The analysis shows that HEIs have experienced an annual average increase in productivity of 1 per cent. Further investigation reveals that HEIs have enjoyed an annual average increase in technology of 6 per cent combined with a decrease in technical efficiency of 5 per cent. Rapid changes in the higher education sector appear to have had a positive effect on the technology of production but this has been achieved at the cost of lower technical efficiency.
\end{abstract}

\section{INTRODUCTION}

Since the early 1990s, the UK higher education sector has experienced some significant changes in its structure and funding. In 1992, the higher education sector expanded to encompass more than 170 institutions (compared with under 60 before that date). Not surprisingly, there is therefore a huge diversity to be seen in the UK higher education sector. UK higher education institutions (HEIs) can be divided into three broad groups on the basis of their historical background. Pre-1992 universities had the status of a university before the provisions of the Further and Higher Education Act of 1992 came into force. Prior to 1992, they were largely funded by the Universities Funding Council. Post-1992 universities are mostly former polytechnics which, prior to 1992, were funded by the Polytechnics and Colleges Funding Councils. The Further and Higher Education Act of 1992 allowed these HEIs to award their own degrees and to use the title of university. The third group of institutions are the colleges that belong to the Standing Conference of Principals Ltd (SCOP). These colleges are part of the higher education sector, but differ from other HEIs in that they are often specialist institutions concentrating on a particular discipline such as teacher training, music, drama, performing arts, education or agriculture. In 2003, it was announced that these specialist institutions will be allowed to apply for university status, and this will be granted on the basis of adequate student numbers and good teaching.

* Manuscript received 17.1.07; final version received 17.1.08.

(C) 2008 The Author

Journal compilation (C) 2008 Blackwell Publishing Ltd and The University of Manchester

Published by Blackwell Publishing Ltd, 9600 Garsington Road, Oxford OX4 2DQ, UK, and 350 Main Street, Malden, MA 02148, USA 
The diversity between these groups of HEIs is matched by the diversity within the groups. The pre-1992 group, for example, includes old universities, such as Oxford and Cambridge, together with the redbricks founded in the 19 th and early 20th centuries, the former colleges of advanced technology and the new universities created in the 1960s. The post-1992 group is somewhat less heterogeneous, most having been founded in the early 20 th century. Historically, post-1992 HEIs have emphasized their teaching activity but, while this is still true for some, over recent years many have successfully established and expanded areas of research. The SCOP colleges primarily engage in teaching, and their diversity derives from the area in which they specialize.

Throughout this period the number of students in higher education has been increasing. Between 1994/95 and 2005/6, for example, full-time undergraduate student numbers in England have risen by 27 per cent and full-time postgraduate student numbers by more than 80 per cent (Higher Education Statistics Agency, 1994/95b, 2005/6b). The Government's stated commitment to expand student numbers up to 50 per cent of the 18-30 age group (Department for Education and Science, 2003) suggests that this rise in numbers will continue.

The expansion in student numbers has necessarily been accompanied by an overhaul of the student-funding process. Student loans were first introduced in 1990. In 1998, students were required to pay up-front fixed rate tuition fees (with some means-testing) and loans were available to cover both fees and living expenses, repaid after graduation and contingent upon income. Since September 2006, up-front fees have been replaced by top-up fees: universities in England are allowed to charge up to $£ 3000$ per year (this is fixed until 2010) and loans at favourable interest rates are available to pay the cost of fees and living, repayment being contingent upon income after graduation.

The UK higher education sector also receives substantial government funding. Since 1994/95, funding council grants to the sector have risen in real terms by 29 per cent up to 2005/6 (Higher Education Statistics Agency, 1994/95a, 2005/6a). The $£ 7544$ million received by the sector in funding council grants in 2005/6, moreover, represents nearly 40 per cent of its total income (Higher Education Statistics Agency, 2005/6a).

The amount of public money received by the sector, and the Government's stated aims for the sector, make it essential to monitor regularly the performance and productivity of the institutions comprising the higher education sector. Flegg et al. (2004) have examined the change in productivity in the British universities sector over the period 1980/81 to $1992 / 93$ using a sample of 45 HEIs. It is therefore no longer representative of the higher education sector which prevails in the UK today. A more recent study by Flegg and Allen (2007) uses a more up-to-date sample (1994-2004) but is restricted only to the pre-1992 universities. An analysis of the performance and productivity of the entire higher education sector is therefore overdue, and this is the gap in the literature which this study aims to fill. 
Measuring the efficiency of institutions in the higher education sector is problematic, however, because the higher education sector has characteristics (some or all of which may also occur in other sectors of the economy) that make it difficult to measure efficiency: it is non-profitmaking; there is an absence of output and input prices; and HEIs produce multiple outputs from multiple inputs. The distance function approach is a particularly attractive method for measuring efficiency in the context of higher education: it does not require a knowledge of input or output prices, nor does it require any specific behavioural assumptions of the firms under consideration, such as cost minimization or profit or revenue maximization (Coelli et al., 1998). When a panel of data is available, moreover, changes in productivity growth over the period under consideration can also be calculated using the Malmquist productivity change index. This index is composed of distance functions, and is therefore superior to alternative indexes of productivity growth (such as the Törnqvist index and the Fisher ideal index) because it is based only on quantity data and makes no assumptions regarding the firm's behaviour (Grifell-Tatjé and Lovell, 1996). The Malmquist productivity index can provide additional insights since it can be decomposed into two additional components, one that measures changes in technical efficiency (i.e. whether firms are getting closer to the production frontier over time) and one that measures changes in technology (i.e. whether the production frontier is moving outwards over time).

There is now a considerable literature on efficiency measurement in the higher education sector, a full survey of which can be found in Worthington (2001) and Johnes (2004). Recent studies of efficiency measurement of UK HEIs include Athanassopoulos and Shale (1997), Glass et al. (2006), Johnes (2006) and Flegg and Allen (2007). Despite the differences between the studies with regard to the time period and HEIs included in the analysis, these studies suggest that the UK higher education sector is remarkably efficient with average efficiency levels of between 85 and 95 per cent. Two additional studies of efficiency in higher education are of particular interest because they analyse productivity changes as well as technical efficiency within higher education. Worthington and Lee (2007) examine the change in productivity in the Australian universities sector between 1998 and 2003, while Flegg et al. (2004) examine the change in productivity in the British universities sector over the period 1980/81 to 1992/93. Both studies find an annual average increase in productivity of more than 3 per cent over the period, and, in both cases, the positive productivity change is found to have been caused largely by positive technological change (i.e. an outwardly shifting production frontier) rather than by changes in technical efficiency.

The purpose of this study is to update and extend the analysis of efficiency and productivity change in the higher education sector. Of particular 
interest is how efficiency and productivity levels compare between the diverse subgroups of the UK higher education sector. To this end, a panel of data from $1996 / 97$ to $2004 / 5$ will form the basis from which to estimate various distance functions which will allow the technical efficiency, technology and productivity change of the sector as a whole, and the subgroups separately, to be assessed over this period.

The paper is in five sections of which this is the first. Section 2 describes how distance functions can be used to measure the various types of efficiency and discusses the estimation methods. The data set and model are described in Section 3 while Section 4 presents the results of the analysis. Finally, conclusions are drawn in Section 5.

\section{Efficiency and Productivity Growth and Their Estimation}

Technical efficiency is defined using Farrell's (1957) approach whereby a firm's actual production point is compared with the point that might have been achieved had it operated on the frontier. In Fig. $1, F^{t}$ represents the constant returns to scale production frontier showing the efficient levels of

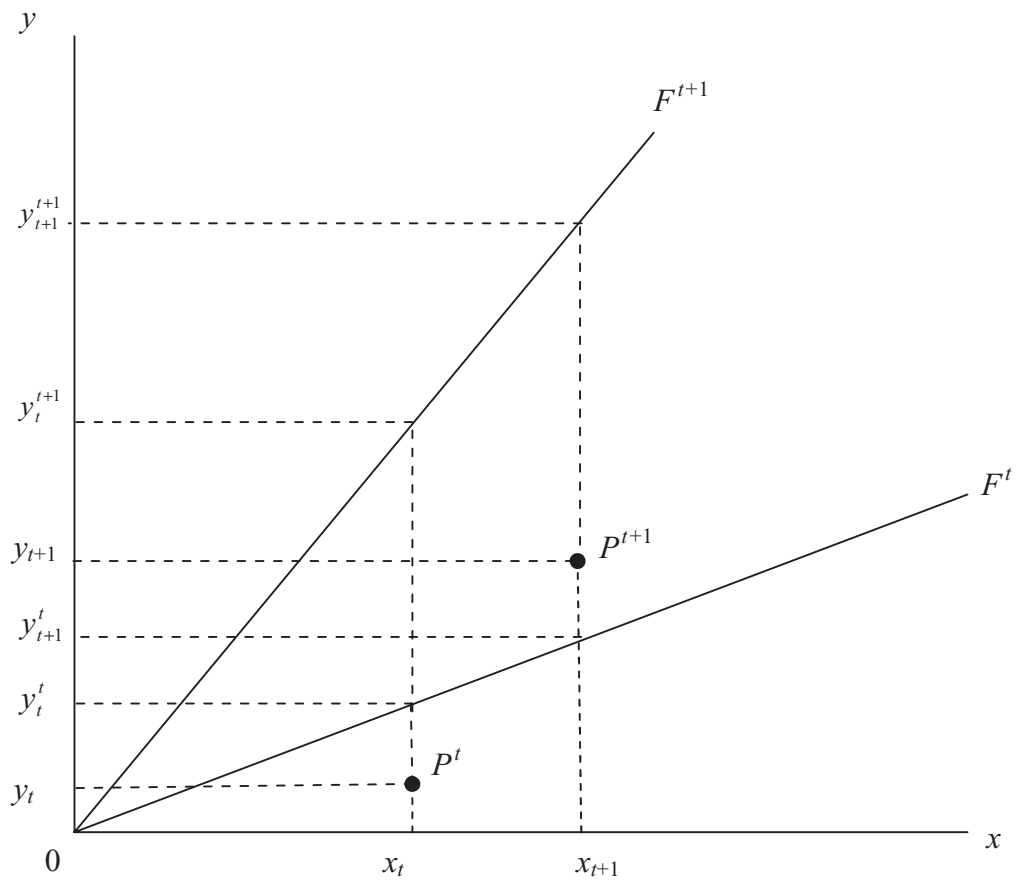

FIG. 1 An Illustration of the Distance Function Approach to Measuring Efficiency and Productivity 
output, $y$, which can be produced, in time $t$, from a given level of input, $x$. Similarly, $F^{t+1}$ represents the constant returns to scale production frontier showing the efficient levels of output, $y$, which can be produced, in time $t+1$, from a given level of input, $x$. University $P$ produces at point $P^{t}$ in time period $t$ and at $P^{t+1}$ in time period $t+1$, and so technical efficiency is measured as the ratio of $0 y_{t} / 0 y_{t}^{t}$ in time period $t$ and by $0 y_{t+1} / 0 y_{t+1}^{t+1}$ in time period $t+1$. This measure is in fact the output distance function which, for the general case, can be denoted by $D_{\mathrm{O}}^{t}\left(x_{t}, y_{t}\right)$ for time $t$ and $D_{\mathrm{O}}^{t+1}\left(x_{t+1}, y_{t+1}\right)$ for time $t+1$ (Coelli et al., 1998).

The time dimension allows an analysis of productivity change which can be measured using the Malmquist productivity index. The approach is standard (and is detailed in Coelli et al., 1998, Ch. 10) and therefore only a short description is provided here. On the assumption that the university seeks to maximize output for a given level of input (i.e. an output-oriented approach), productivity change might be evaluated by comparing the efficiencies of observations $P^{t}$ and $P^{t+1}$ calculated relative to the frontier in period $t$ (i.e. $\left(0 y_{t+1} / 0 y_{t+1}^{t}\right) /\left(0 y_{t} / 0 y_{t}^{t}\right)$ in Fig. 1) or by comparing the efficiencies of $P^{t}$ and $P^{t+1}$ calculated relative to the frontier in period $t+1$ (i.e. $\left(0 y_{t+1} / 0 y_{t+1}^{t+1}\right) /\left(0 y_{t} / 0 y_{t}^{t+1}\right)$ in Fig. 1). In practice, the Malmquist approach takes a geometric mean of the two measures and the general formula for the Malmquist productivity change index is (Coelli et al., 1998)

$$
M_{\mathrm{O}}\left(x_{t+1}, y_{t+1}, x_{t}, y_{t}\right)=\left[\left(\frac{D_{\mathrm{O}}^{t}\left(x_{t+1}, y_{t+1}\right)}{D_{\mathrm{O}}^{t}\left(x_{t}, y_{t}\right)}\right)\left(\frac{D_{\mathrm{O}}^{t+1}\left(x_{t+1}, y_{t+1}\right)}{D_{\mathrm{O}}^{t+1}\left(x_{t}, y_{t}\right)}\right)\right]^{1 / 2}
$$

where $D_{\mathrm{O}}^{t}\left(x_{t+1}, y_{t+1}\right)$ denotes the distance of the period $t+1$ observation from the period $t$ frontier. If the Malmquist productivity change index exceeds unity, there has been an improvement in productivity between periods $t$ and $t+1$. Values less than 1 suggest the converse.

It can be seen from Fig. 1 that the change in the production position of university $P$ over the two time periods has two underlying determinants: first, the university can produce more because the sector's production frontier has moved outwards, and therefore the potential for production is expanded; second, the university's position relative to the time-relevant frontier can change. The Malmquist productivity index conceals these two effects. However, it is possible to decompose it into the two components as follows (Färe et al., 1989, 1994):

$$
M_{\mathrm{O}}\left(x_{t+1}, y_{t+1}, x_{t}, y_{t}\right)=\frac{D_{\mathrm{O}}^{t+1}\left(x_{t+1}, y_{t+1}\right)}{D_{\mathrm{O}}^{t}\left(x_{t}, y_{t}\right)}\left[\left(\frac{D_{\mathrm{O}}^{t}\left(x_{t+1}, y_{t+1}\right)}{D_{\mathrm{O}}^{t+1}\left(x_{t+1}, y_{t+1}\right)}\right)\left(\frac{D_{\mathrm{O}}^{t}\left(x_{t}, y_{t}\right)}{D_{\mathrm{O}}^{t+1}\left(x_{t}, y_{t}\right)}\right)\right]^{1 / 2}
$$

The first component

$$
E=\frac{D_{\mathrm{O}}^{t+1}\left(x_{t+1}, y_{t+1}\right)}{D_{\mathrm{O}}^{t}\left(x_{t}, y_{t}\right)}
$$


measures the change in technical efficiency over the two periods (i.e. whether or not the unit is getting closer to its efficiency frontier over time), and the second component

$$
T=\left[\left(\frac{D_{\mathrm{O}}^{t}\left(x_{t+1}, y_{t+1}\right)}{D_{\mathrm{O}}^{t+1}\left(x_{t+1}, y_{t+1}\right)}\right)\left(\frac{D_{\mathrm{O}}^{t}\left(x_{t}, y_{t}\right)}{D_{\mathrm{O}}^{t+1}\left(x_{t}, y_{t}\right)}\right)\right]^{1 / 2}
$$

measures the change in technology over the two time periods (i.e. whether or not the frontier is shifting out over time). Values of either of these components of greater than unity suggest improvement, while values of less than 1 suggest the opposite.

In the exposition so far, constant returns to scale (CRS) have been assumed. We can relax the CRS assumption and assume variable returns to scale (VRS). The ratio of the CRS to VRS technical efficiency measures (i.e. $\mathrm{SE}^{t}=D_{\mathrm{O}, \mathrm{CRS}}^{t} / D_{\mathrm{O}, \mathrm{VRS}}^{t}$, where the returns to scale are now denoted in the subscript) provides an estimate of the scale efficiency of the units under consideration in period $t$. If $\mathrm{SE}^{t}$ is equal to 1 then the unit is already at its optimum scale size in period $t$.

With regard to returns to scale and productivity change, Färe et al. $(1994,1997)$ propose a further decomposition of the Malmquist index such that $E=\mathrm{PE} \times S$ where $E$ is the efficiency change calculated on the assumption of CRS (defined above);

$$
\mathrm{PE}=\frac{D_{\mathrm{O}, \mathrm{VRS}}^{t+1}\left(x_{t+1}, y_{t+1}\right)}{D_{\mathrm{O}, \mathrm{VRS}}^{t}\left(x_{t}, y_{t}\right)}
$$

and is the pure technical efficiency change index; and $S=\mathrm{SE}^{t+1} / \mathrm{SE}^{t}$ for periods $t$ and $t+1$ (where $\mathrm{SE}^{t}$ is defined above), and $S$ measures the degree to which a unit gets closer to its most productive scale size over the periods under examination. Any empirical estimation of this decomposition of the Malmquist productivity change index should be treated with caution, however, since it mixes VRS and CRS efficiencies in the estimation of its components (Ray and Desli, 1997).

The distance functions required to evaluate these various measures of efficiency and productivity can be estimated using parametric or non-parametric techniques. The most common methods are stochastic frontier analysis (SFA) and data envelopment analysis (DEA). Both of these estimate a production frontier, but in the former case the frontier is parametric, while in the latter it is a non-parametric piece-wise linear frontier that envelops the data. SFA requires assumptions to be made regarding the distribution of efficiencies, the distribution of the stochastic errors and the functional form of the production technology. The advantage of these assumptions is that it allows statistical inferences to be drawn from the results. The disadvantages derive from the fact that the assumptions are often made in an arbitrary fashion, or for reasons of analytical 
tractability, rather than from a knowledge of the true distributions or functional form.

DEA requires no such assumptions and hence estimates of technical efficiencies are free of possible errors resulting from incorrect assumptions. The downside of this is that statistical inferences cannot be drawn from the DEA results. In addition, in not allowing for the possibility of stochastic error, DEA may incorporate in its estimates of efficiency errors arising from random fluctuations. An attractive feature of DEA, which is particularly pertinent for the present study, is that it allows the weights assigned to each input and output to vary by observation. This means that no unit can be penalized by taking an unorthodox production approach, as it might be by the imposition of a uniform set of weights across all units. SFA, in contrast, imposes the same input and output parameters on all observations (recent developments in SFA allow for a random parameters variant - see Johnes and Johnes (forthcoming) - but this requires additional distributional assumptions and imposes considerable strain on the data). The wide diversity of units included in this analysis, along with the multiple input, multiple output nature of production in higher education, makes DEA the technique of choice in the ensuing analysis.

The CRS distance functions required to estimate the Malmquist productivity index $\left(M_{\mathrm{O}}^{t}\right)$ are calculated using linear programming (see Coelli et al., 1998 , p. 227, for details). The linear programmes are easily adapted to allow estimation of the VRS distance functions required to provide estimates of pure technical and scale efficiency.

There are two approaches to calculating the Malmquist productivity change index (Grifell-Tatjé and Lovell, 1996). First, it can be calculated for each pair of adjacent years from $t, t+1$ to $T-1, T$ (for $t=1, \ldots, T$ ). Alternatively, it can be calculated for each year relative to the same fixed base (i.e. for $t$ relative to $s, t+1$ relative to $s$, and so on to $T$ relative to $s$ ). The value of the Malmquist productivity change index can vary according to the method used, particularly if production frontiers in adjacent periods overlap (Grifell-Tatjé and Lovell, 1996). Both methods will therefore be applied in the ensuing analysis.

\section{Data And Model}

Taking a production approach, universities can be seen as using raw materials, capital and labour inputs to produce teaching, research and social outputs. The difficulties of creating variables to measure these broad categories of inputs to and outputs from the higher education production process are, by now, well known (a summary of these can be found in Johnes, 2004). As has already been observed, there is a wide diversity of HEIs included in the analysis, and any attempt to identify a uniform set of inputs and outputs for such a diverse set is bound to be open to criticism. While this problem should 
be borne in mind when interpreting the results, it is also important to remember that the estimation technique also plays a part in reducing this problem because it allows each unit to impose its own set of input and output weights to reflect it in its best possible light. The inputs and outputs defined in the present study are constructed from detailed annual statistics for all HEIs in England published by the Higher Education Statistics Agency (HESA). These statistics cover resources, students and staff numbers, and the first destinations of graduates.

Five measures of inputs are constructed from the data and detailed definitions can be found in Table 1. Raw materials are the student inputs as measured by the number of full-time equivalent (FTE) first-degree and other undergraduates (UG) and the number of FTE postgraduate students

TABLE 1

DEFINITIONS OF INPUTS AND OUTPUTS

\begin{tabular}{|c|c|}
\hline Variable name & Definition \\
\hline \multicolumn{2}{|l|}{ Inputs } \\
\hline STAFF & $\begin{array}{l}\text { The number of full-time academic staff plus } 0.5 \text { times the number of } \\
\text { part-time academic staff }\end{array}$ \\
\hline $\mathrm{ADMIN}^{\mathrm{a}}$ & $\begin{array}{l}\text { Expenditure on total administration and central services including } \\
\text { expenditure on staff and student facilities (including, for example, } \\
\text { Careers Advisory Service, all grants to student societies, emoluments } \\
\text { to wardens of halls of residence, accommodation office, athletic and } \\
\text { sporting facilities, excluding maintenance, and the institution's health } \\
\text { service) and general educational expenditure }\end{array}$ \\
\hline ACSERV $^{\mathrm{a}}$ & $\begin{array}{l}\text { Expenditure incurred on centralized academic services such as the library } \\
\text { and learning resource centres, central computer and computer } \\
\text { networks, centrally run museums, galleries and observatories, and any } \\
\text { other general academic services }\end{array}$ \\
\hline UG & $\begin{array}{l}\text { The total number of FTE first-degree and other undergraduates. The } \\
\text { 'other undergraduates' category includes qualification aims below } \\
\text { degree level such as Foundation Degrees and Higher National } \\
\text { Diploma (HND) }\end{array}$ \\
\hline PG & $\begin{array}{l}\text { The total number of FTE postgraduate students (i.e. students on } \\
\text { programmes of study leading to higher degrees, diplomas and } \\
\text { certificates, including Postgraduate Certificate of Education (PGCE) } \\
\text { and professional qualifications) }\end{array}$ \\
\hline \multicolumn{2}{|l|}{ Outputs } \\
\hline UGOUTPUT & $\begin{array}{l}\text { The number of first-degree and other undergraduate qualifications } \\
\text { awarded (see definition of UG) }\end{array}$ \\
\hline PGOUTPUT & $\begin{array}{l}\text { The number of higher-degree qualifications plus total other postgraduate } \\
\text { qualifications awarded (including doctorate, other higher degrees, } \\
\text { PGCEs and other postgraduate qualifications) }\end{array}$ \\
\hline $\mathrm{RESEARCH}^{\mathrm{a}}$ & $\begin{array}{l}\text { Income received in funding council grants plus income received in } \\
\text { research grants and contracts (in thousands) }\end{array}$ \\
\hline
\end{tabular}

Source: HESA, Resources of Higher Education Institutions, various volumes; Students in Higher Education Institutions, various volumes.

Notes: ${ }^{a}$ These variables are deflated to January 2003 values using the higher education pay and prices index (http://www.universitiesuk.ac.uk/statistics/heppi/default.asp).

${ }^{\mathrm{b}} \mathrm{A}$ full description of students included in these categories can be found in the HESA data documentation. 
(PG). Capital input is measured using the variable ACSERV, which is expenditure on centralized academic services such as the library and computing services. Labour input is measured by the number of FTE academic staff (STAFF). It should be noted that non-academic labour inputs are not directly incorporated. The data published by HESA do not provide a breakdown of staff type over the entire time period of the study. For 2004/5 where a breakdown is available, the correlation between academic and non-academic staff numbers is 0.97 and so the non-academic staff input may actually be reflected, to some extent, by the academic staff numbers. In addition, another input variable is included in an attempt to capture the non-academic input into the university production process. This additional variable is ADMIN, which is expenditure on total administration and central services. As in previous studies (Abbott and Doucouliagos, 2003; Flegg et al., 2004; Flegg and Allen, 2007; Worthington and Lee, 2007), no attempt is made to take into account inter-institution differences in quality of inputs (quality may vary substantially by institution in the context of the raw material and labour inputs), mainly because of a lack of published data in this area, and this should be borne in mind when interpreting the results.

Three measures of output are constructed, and detailed definitions can be found in Table 1. The number of first-degree and other undergraduate degree qualifications (UGOUTPUT) and the number of higher and other postgraduate degree qualifications (PGOUTPUT) measure the teaching output of HEIs, and these tie in with the respective raw material input measures (UG and PG). As with student input, these measures are not adjusted at all for quality, and this is consistent with models defined in previous studies (Athanassopoulos and Shale, 1997; Flegg and Allen, 2007; Worthington and Lee, 2007). While it would be possible to make some adjustment for quality of undergraduate output, such as using the number of graduates achieving a particular class of degree (Flegg et al., 2004; Flegg and Allen, 2007), this has not been done because counting only the number of graduates in a particular class assumes that the remaining graduates are of no value and is therefore also very unsatisfactory.

Research output might be measured using income received for research purposes or by using the ratings of university departments' research produced by the Research Assessment Exercise. The latter might be considered a more appropriate measure of research output, incorporating both quality and, if weighted by appropriate staff numbers, quantity (Glass et al., 2006). The Research Assessment Exercise ratings, however, are available only at intervals (1996 and 2001 over the study period) whereas the analysis is based on annual data. Hence income received for research purposes is used as the measure of research output (RESEARCH). This approach is now firmly rooted in the literature because of its ease of availability and because it provides an up-to-date measure of both the quality and quantity of research 
(Abbott and Doucouliagos, 2003; Flegg et al., 2004; Flegg and Allen, 2007; Worthington and Lee, 2007).

After teaching and research, universities are also considered to produce 'third mission' or social output. Included in this are the storage and preservation of knowledge and skills; the provision of advice and other services to business; and the provision of a source of independent comment on public issues. No attempt is made to construct a separate measure of the social outputs of HEIs, and there may therefore be bias in the results as a consequence of this omission.

It was possible to collect the data required and to construct these variables for nine years (1996/97 to 2004/5), and for a total of 112 HEIs in England. This figure is less than the total number of institutions in the sector in England for a number of reasons: data for HEIs that merged during the study period are amalgamated for years prior to the merger; HEIs that entered the sector during the study period are not included; HEIs for which a full set of data was not available, or that produced zero of any output (thereby being outliers and affecting the DEA results) have been removed; Open University has also been removed because of its large size and its unique nature of teaching provision. It should also be noted that any variables measured in monetary terms have been standardized to January 2003 values (see Table 1). Descriptive statistics are presented for all measures (amalgamated across all years), and for each subgroup separately, in Table 2. It is clear that the post-1992 group of HEIs have the largest average number of undergraduates, and also display the least diversity in terms of the coefficient of variation (CV) of the respective input and output measures. Pre-1992 HEIs have the largest average number of postgraduates and research output. The SCOPs and SCOP-type institutions are the smallest in size, on the basis of mean score on all of the input and output measures. The trend over time for all measures (not shown in the table) is generally upward, and this is particularly marked for the last four years of the series, i.e. since 2001/2.

\section{Results}

\subsection{Technical and Scale Efficiency}

All efficiency and productivity measures have been calculated using the software PIM-DEAsoft V1. Two alternative approaches are taken to the estimation of efficiencies because of the considerable diversity between the different types of HEIs in terms of their input and output structure. First, because it has previously been found that the efficiency with which these inputs are converted into outputs does not differ significantly across the subgroups of HEIs (Johnes, 2006), DEA is applied across the entire sample of HEIs. Second, to provide results for comparison, and to reduce the possible problem of outliers in such a diverse data set, DEA is applied to each 


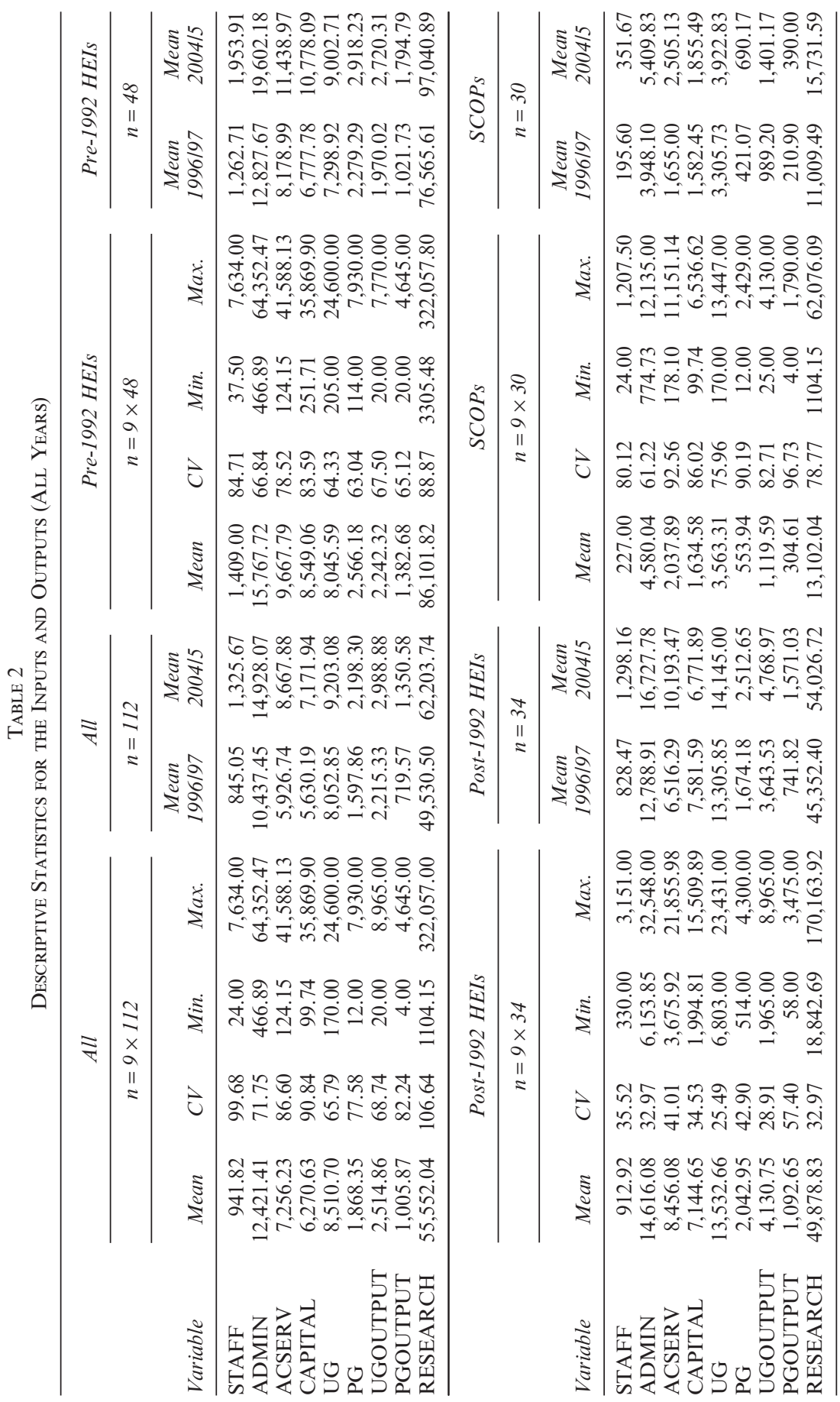

(C) 2008 The Author

Journal compilation @ 2008 Blackwell Publishing Ltd and The University of Manchester 2008 
subgroup separately, thereby allowing a member of a subgroup only to have members of the same subgroup in its efficient reference set. The resulting efficiency scores derived from the two alternative approaches are summarized in Table 3. It is no surprise that the efficiency scores derived from the second approach are, on average, higher (by about 6 percentage points) than those derived from the first approach.

Average overall technical efficiency over the period for the sector as a whole is high (88 or 95 per cent, depending on the approach taken). The efficiencies from the second approach are in line with previous studies which are comparable in terms of either time period or sample of HEIs included (e.g. Johnes, 2006; Flegg and Allen, 2007). The lower efficiencies from the first approach are more comparable with efficiency levels found for alternative samples covering earlier periods (Flegg et al., 2004; Glass et al., 2006).

While average efficiency over all years is high, there is wide variation between HEIs and over time. The minimum efficiency score for an individual HEI (around 50 per cent) is observed in 2000/1, a year in which average efficiency dips noticeably (relative to the years either side). Since 2001/2, technical efficiency appears to have been on a downward trend. Scale and, to a lesser extent, pure technical efficiency scores display a similar pattern. These general patterns are observed in the results of both estimation approaches.

The figures for the overall sector conceal some differences between the subgroups. SCOP and SCOP-type colleges, for example, have higher average overall technical efficiency and higher scale efficiency than pre-1992 HEIs. There appears to be little difference between the subgroups, however, in terms of pure technical efficiency. A Kruskal-Wallis test was applied to each of the sets of efficiencies (i.e. overall, pure and scale) by year and averaged across all years. The results indicate that the overall technical and scale efficiency distributions of the three subgroups are, on average, significantly different at the 5 per cent significance level. These findings are observed regardless of the approach taken to estimate the efficiencies.

It is well known that DEA results can be sensitive to the specification of the inputs and outputs. As a consequence several alternative models were defined and efficiencies evaluated. First STAFF in the original model was replaced by two separate variables measuring part-time academic staff and full-time academic staff; second, an alternative measure of capital (namely depreciation costs and interest payable) replaced ACSERV and ADMIN in the original model; finally this alternative measure of capital was included as an additional input in the original model. In all cases, the pattern of efficiencies was similar to those reported.

The high levels of technical efficiency derived in this and other studies of the English higher education sector warrant further examination, particularly since this is a sector without a profit motivation. One obvious possible reason for the results derives from a shortcoming of the DEA technique: efficiency is measured relative to an observed production frontier (i.e. one determined by 


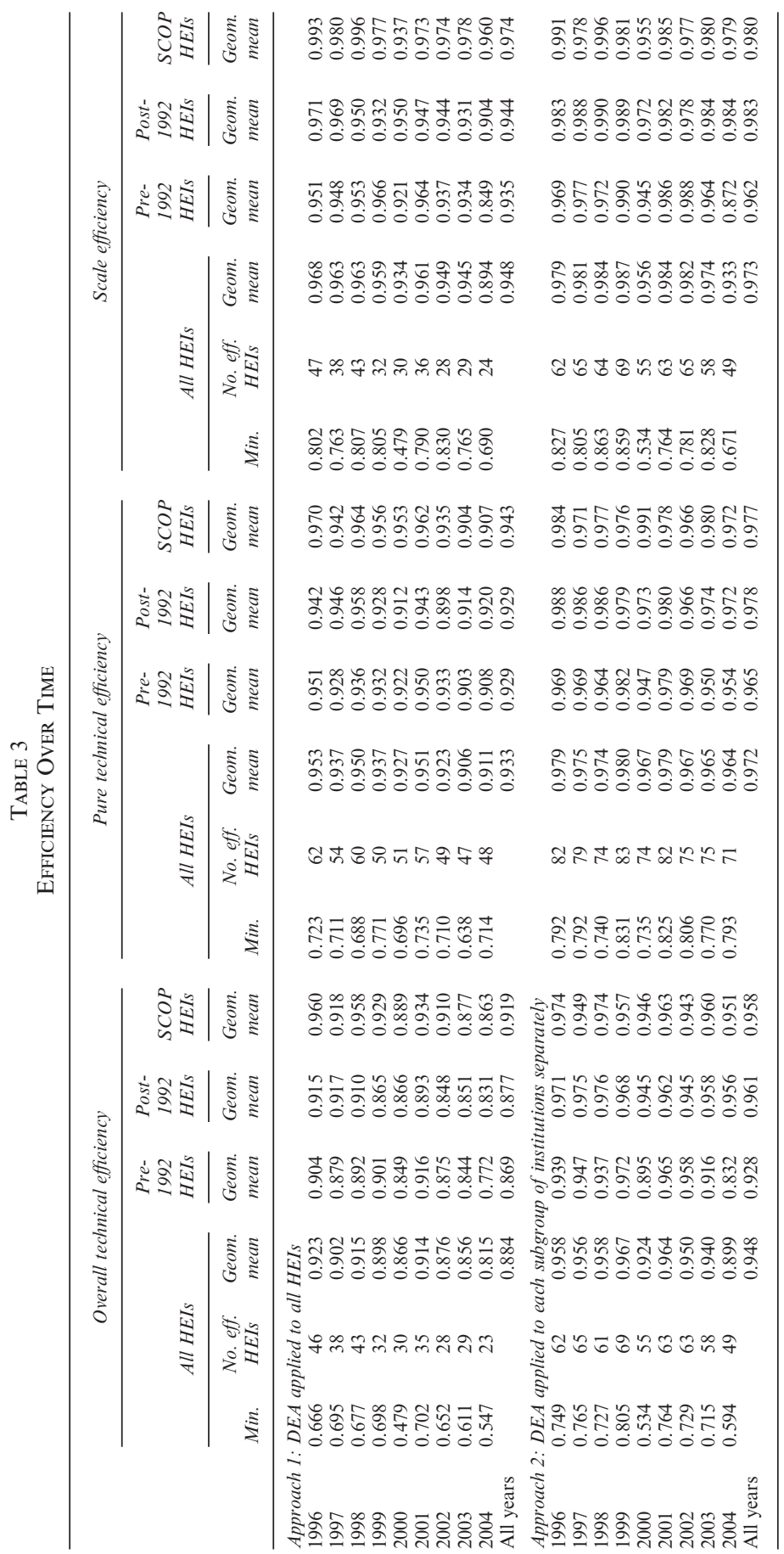


the observations in the sample), and this may differ from the true frontier for an efficient higher education sector. Even if this is the case and efficiency is therefore overestimated, the rankings and interrelationships between the HEIs are still likely to be valid. A second point to consider is that, over the decade covered by this study, competitive forces have increasingly entered the English higher education sector. HEIs must increasingly compete for the best students and for resources with which to conduct research. The incentive to be efficient is therefore present, even though the profit motivation is not. This begs the question of why efficiency levels appear to have been falling in the most recent years of the study (since 2001/2), a period that has also experienced the most rapid expansion. This will be considered in further detail in the context of the productivity indexes discussed below.

\subsection{Productivity Changes}

Changes in productivity over the period of study are calculated using both an adjacent-year and a base-year approach (see Section 2). The results are consistent across both approaches and so only the results of the base-year approach are reported. In addition, productivity changes are assessed using both across-sample and within-subgroup estimation approaches (as with the efficiencies in Section 4.1). The results of these two approaches are reported in Table 4 . The results are broadly similar. The following text refers to the results reported in Table 4, part (a). Over the period as a whole, the annual average Malmquist productivity change, relative to 1996/ 97, is around only 1 per cent. Productivity has fluctuated widely, however, from around -4 per cent in 2004/5 (relative to 1996/97) to 7 per cent in 2003/4 (relative to 1996/97).

From an examination of the components of the Malmquist productivity index, it emerges that technology change has averaged around 6 per cent per annum, and that the Malmquist index has been brought down by a negative annual average technical efficiency change of -5 per cent. The small average annual increase in productivity in English higher education over the period is therefore largely a consequence of technology change rather than technical efficiency change, and this is consistent with previous studies (Flegg et al., 2004; Worthington and Lee, 2007). These findings are also confirmed when the second approach to the estimation of the indexes is taken.

This broad pattern of positive technology change outweighing negative technical efficiency change (when averaged across all years) is also observed for each subgroup separately. There are some small differences between the subgroups in the size of the indexes: technology change, for example, has been slightly higher, on average, for the post-1992 and SCOP and SCOP-type colleges than for pre-1992 HEIs (7 per cent compared with 5 per cent). A Kruskal-Wallis test was applied to each of the sets of indexes (i.e. technical efficiency change, technology change and Malmquist productivity change) by 


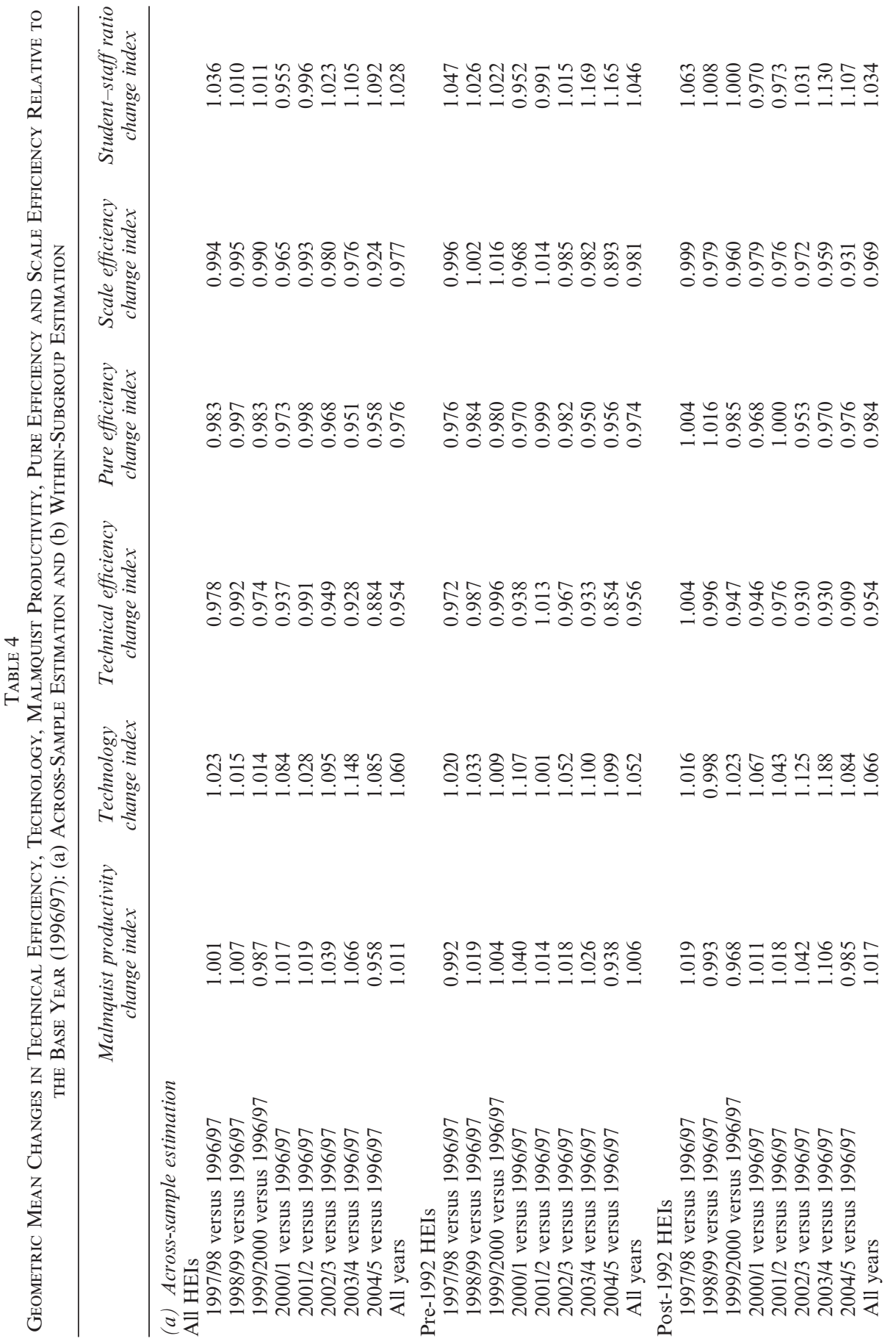

(C) 2008 The Author

Journal compilation (C 2008 Blackwell Publishing Ltd and The University of Manchester 2008 


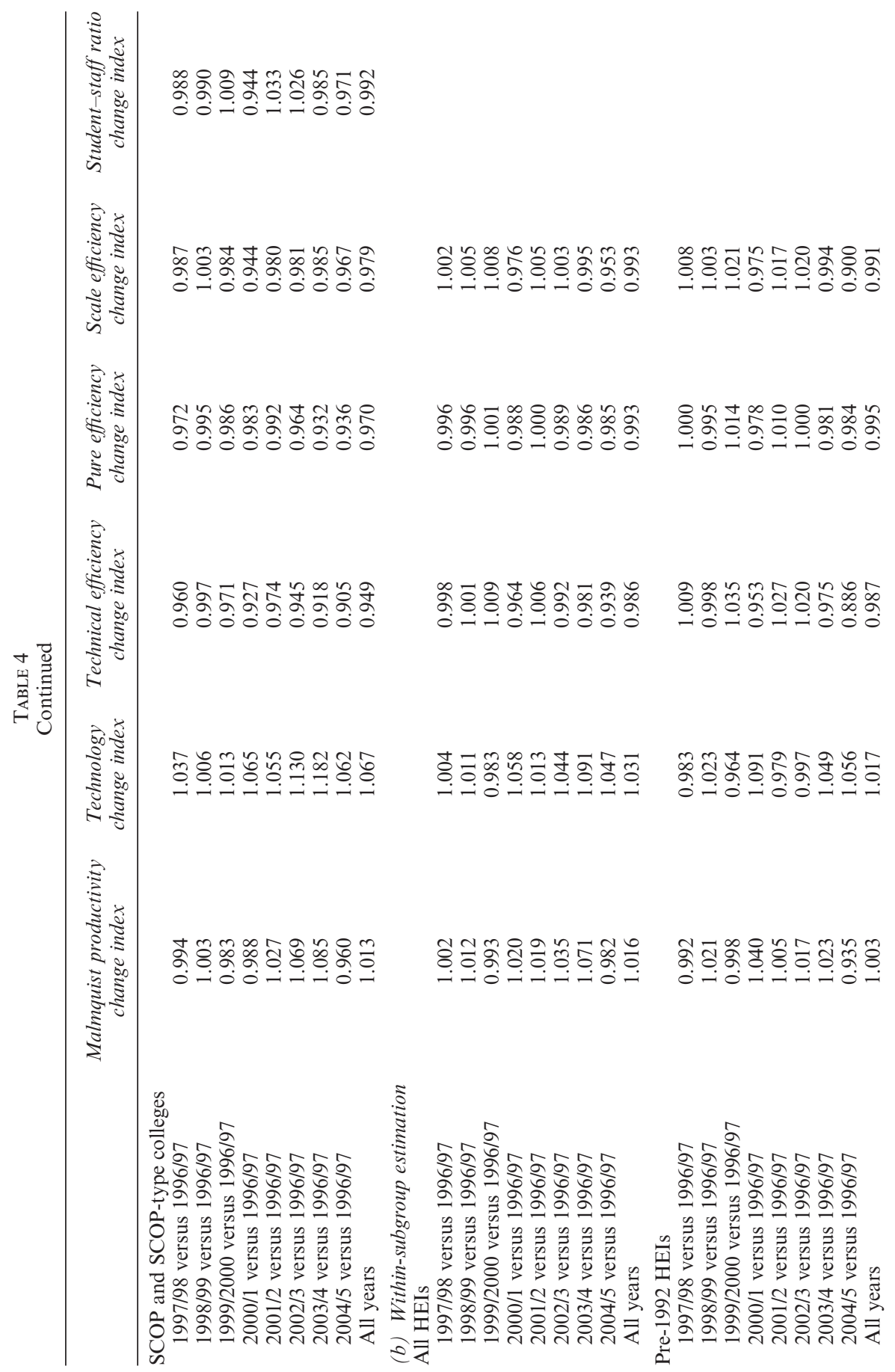




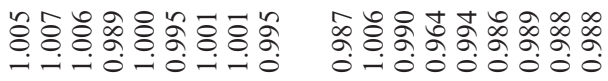

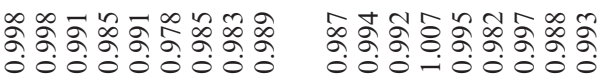

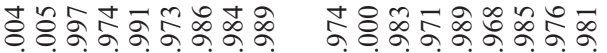
-4.-808080

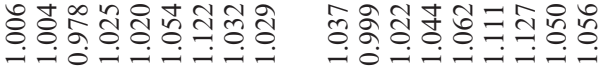

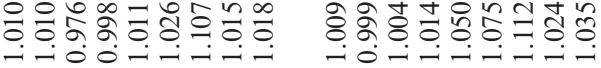

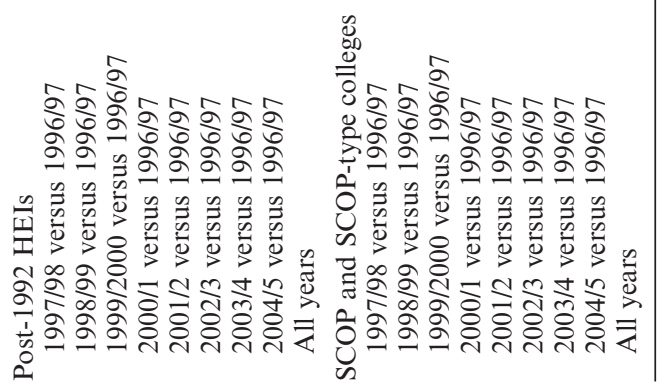


year and averaged across all years. The results indicate that the technology change distributions of the three subgroups are significantly different, on average, at the 5 per cent significance level. There is no significant difference between subgroups in the distributions of technical efficiency change and Malmquist productivity change. These findings are observed regardless of the approach taken to estimate the indexes.

The technical efficiency change component can be divided into two further components, namely pure technical efficiency change and scale efficiency change. These figures should be treated with a degree of caution first for the reasons outlined in Section 2, and second because they are calculated on the assumption that there is no congestion in the higher education production process (Flegg and Allen, 2007). Broadly speaking, both scale and pure technical efficiency changes contribute equally to the annual average technical efficiency change.

The most obvious source of change in production activity in HEIs is the increased use of information technology and e-learning. The Department for Education and Skills has highlighted the improvements introduced by increased use of technology: information is more accessible to users, causing changes in teaching, and increasing the efficiency of administrators (Department for Education and Science, 2005). Improved communications have also increased the ease with which collaborative research can be undertaken. Thus all aspects of a university's activities are affected by increasing use and application of technology.

What reasons can then be offered for the observed negative changes in technical efficiency over the period? It is clear from Table 4, part (a), that influences in the period around 2000/1 had severe effects on productivity: there was a relatively large increase in technology but this was accompanied by a severe drop in technical efficiency. This is observed, moreover, in all subsectors of the higher education sector. Thus, factors pushing out the production frontier (such as the introduction of information technology and e-learning into universities) may have a detrimental effect on, or may be accompanied by a fall in, technical efficiency. For example, increased use of e-technology in teaching may allow class sizes to increase, or might have been adopted in response to class sizes. Yet an increasing ratio of students to staff may have an adverse effect on technical efficiency (e.g. student achievement rates and research levels may be affected). The annual index of change (relative to 1996/97) in the ratio of students to staff, reported in Table 4, part (a), reveals that, for the sector as a whole, the changing student-staff ratio has been broadly in line with the technology change index (with the exception of the year 2000/1). Since the year 2000/1, the trend has been for decreases in the technical efficiency change index to occur simultaneously with increases in the student-staff ratio. This pattern is also observed within the subgroups of pre- and post-1992 HEIs. No such pattern can be observed, however, within the subgroup of SCOP and SCOP-type colleges, where changes in the ratio of 
TABLE 5

Geometric Mean Changes in Technical Efficiency, Technology and Student-Staff Ratio Relative to the Base Year (1996/97)—Two HeIs Performing at the Extremes

\begin{tabular}{lcccc}
\hline & $\begin{array}{c}\text { Malmquist } \\
\text { productivity } \\
\text { change index }\end{array}$ & $\begin{array}{c}\text { Technology } \\
\text { change index }\end{array}$ & $\begin{array}{c}\text { Technical } \\
\text { efficiency } \\
\text { change index }\end{array}$ & $\begin{array}{c}\text { Student-staff } \\
\text { ratio change } \\
\text { index }\end{array}$ \\
\hline HEI with poor productivity performance & & & \\
1997/98 versus 1996/97 & 0.980 & 1.020 & 0.970 & 1.049 \\
1998/99 versus 1996/97 & 0.860 & 0.990 & 0.870 & 1.111 \\
1999/2000 versus 1996/97 & 0.730 & 0.980 & 0.750 & 1.082 \\
2000/1 versus 1996/97 & 0.780 & 1.010 & 0.780 & 1.022 \\
2001/2 versus 1996/97 & 0.770 & 1.010 & 0.760 & 1.033 \\
2002/3 versus 1996/97 & 0.730 & 1.050 & 0.700 & 0.957 \\
2003/4 versus 1996/97 & 0.770 & 1.080 & 0.710 & 1.097 \\
2004/5 versus 1996/97 & 0.700 & 1.100 & 0.640 & 1.065 \\
HEI with good productivity performance & & & 0.992 \\
1997/98 versus 1996/97 & 1.040 & 1.010 & 1.030 & 0.905 \\
$1998 / 99$ versus 1996/97 & 1.030 & 1.010 & 1.020 & 1.023 \\
$1999 / 2000$ versus 1996/97 & 1.110 & 1.080 & 1.030 & 1.050 \\
2000/1 versus 1996/97 & 1.330 & 1.090 & 1.220 & 1.079 \\
2001/2 versus 1996/97 & 1.320 & 1.080 & 1.220 & 1.017 \\
2002/3 versus 1996/97 & 1.540 & 1.260 & 1.220 & 1.129 \\
2003/4 versus 1996/97 & 1.520 & 1.250 & 1.220 & 1.284 \\
2004/5 versus 1996/97 & 1.250 & 1.040 & 1.210 & \\
\hline
\end{tabular}

students to staff have, in any case, been much less than in the other two subgroups.

In order to assess the limitations of the analysis of the sector as a whole provided so far, an examination of the pattern of performance for two HEIs performing at the extremes is reported in Table 5. The 'poor performer' (i.e. an HEI with average Malmquist productivity change index in the lower quartile) which is above average in size (based on its inputs and outputs) has falling Malmquist productivity, and this is mainly a consequence of falling technical efficiency. The student-staff ratio change index and technology change index are at similar levels and follow a broadly similar pattern, as is the case for the sector as a whole. The pattern is different, however, for the 'good performer' (i.e. an HEI with an average Malmquist productivity change index in the upper quartile). Malmquist productivity for this HEI, which is a little below average size (based on its inputs and outputs), is a consequence of general increases in both technical efficiency and technology, and the student-staff ratio change index is less closely related to the technology change index, particularly since 2001/2, than is the case for the sector as a whole. Clearly the changing student-staff ratio in the English higher education sector can only offer a partial explanation for the observed increase in the technology change index (and decrease in the technical efficiency change index), and further research is necessary to examine this issue at the level of individual HEIs. 


\section{Conclusion}

This study has used DEA and distance functions to derive Malmquist productivity change indexes for the English higher education sector over the period 1996/97 to 2004/5. The Malmquist productivity change indexes have been decomposed into technical efficiency change indexes (which reveal whether HEIs are getting closer to the production frontier) and technology change indexes (which reveal whether the production frontier is moving outwards).

Over the period of the study, Malmquist productivity has risen by an annual average of 1 per cent relative to the base year 1996/97, and this has been caused by a combination of positive annual average technology change (6 per cent) and negative annual average technical efficiency change (around -5 per cent). While technology change has been found to be an important component of Malmquist productivity change in other studies of higher education (Flegg et al., 2004; Worthington and Lee, 2007), the finding of negative technical efficiency change is new. This is a worrying finding since it suggests that while HEIs have attempted to respond to the Government's desire for expansion in the higher education sector by changing their technology, they are doing so at the price of technical efficiency.

There have been some differences in performance across the subgroups of HEIs. SCOP and SCOP-type colleges have higher overall and scale efficiency, on average, than pre-1992 HEIs, and this difference is significant. All three subgroups have experienced negative technical efficiency change and positive technology change. But post-1992 HEIs and SCOP and SCOP-type colleges have experienced higher technology change indexes than pre-1992 HEIs. Once more, this difference is significant.

A further examination of the productivity indexes reveals that, with the exception of 2001/2, the technology change index has generally moved in a similar pattern to the index of change in the student-staff ratio for the sector as a whole. This is also the case for pre- and post-1992 HEIs, but is not so for the SCOP colleges. So, while changes in teaching practices to accommodate increasing student numbers in the pre- and post-1992 HEIs may partially account for the increase in technology change (i.e. the pushing out of the production frontier), this is clearly not the case for all institutions. Moreover, the decrease in technical efficiency occurring simultaneously with the increasing technology is a worrying observation, and suggests that institutions need time to adapt to the changing technology.

\section{REFERENCES}

Abbott, M. and Doucouliagos, C. (2003). 'The Efficiency of Australian Universities: a Data Envelopment Analysis', Economics of Education Review, Vol. 22, No. 1, pp. 89-97. 
Athanassopoulos, A. D. and Shale, E. (1997). 'Assessing the Comparative Efficiency of Higher Education Institutions in the UK by Means of Data Envelopment Analysis', Education Economics, Vol. 5, No. 2, pp. 117-134.

Coelli, T., Rao, D. S. P. and Battese, G. E. (1998). An Introduction to Efficiency and Productivity Analysis, Norwell, MA, Kluwer Academic.

Department for Education and Science (2003). 'The Future of Higher Education', White Paper. http://www.dfes.gov.uk/hegateway/strategy/hestrategy/pdfs/DfESHigherEducation.pdf.

Department for Education and Science (2005). 'Harnessing Technology: Transforming Learning and Children's Services', http://www.dfes.gov.uk/publications/estrategy/docs/e-strategy.pdf.

Färe, R., Grosskopf, S. and Weber, W. L. (1989). 'Measuring School District Performance', Public Finance Quarterly, Vol. 17, No. 4, pp. 409-428.

Färe, R., Grosskopf, S., Norris, M. and Zhang, Z. (1994). 'Productivity Growth, Technical Progress and Efficiency Change in Industrialized Countries', American Economic Review, Vol. 84, No. 1, pp. 66-83.

Färe, R., Grosskopf, S. and Norris, M. (1997). 'Productivity Growth, Technical Progress and Efficiency Change in Industrialized Countries: Reply', American Economic Review, Vol. 87, No. 5, pp. 1040-1043.

Farrell, M. (1957). 'The Measurement of Productive Efficiency', Journal of the Royal Statistical Society, Series A, Vol. 120, pp. 253-281.

Flegg, A. T. and Allen, D. O. (2007). 'Does Expansion Cause Congestion? The Case of the Older British Universities, 1994-2004', Education Economics, Vol. 15, No. 1, pp. 75-102.

Flegg, A. T., Allen, D. O., Field, K. and Thurlow, T. W. (2004). 'Measuring the Efficiency of British Universities: a Multi-period Data Envelopment Analysis', Education Economics, Vol. 12, No. 3, pp. 231-249.

Glass, J. C., McCallion, G., McKillop, D. G., Rasaratnam, S. and Stringer, K. S. (2006). 'Implications of Variant Efficient Measures for Policy Evaluations in UK Higher Education', Socio-Economic Planning Sciences, Vol. 40, pp. 119 142.

Grifell-Tatjé, E. and Lovell, C. A. K. (1996). 'Deregulation and Productivity Decline: the Case of Spanish Savings Banks', European Economic Review, Vol. 40, pp. 1281-1303.

Higher Education Statistics Agency (1994/95a). 'Resources of Higher Education Institutions, Cheltenham, http://www.hesa.ac.uk/index.php?option=com datatables\&Itemid=121\&task=show_category\&catdex $=1$.

Higher Education Statistics Agency (1994/95b). 'Students in Higher Education Institutions, Cheltenham', http://www.hesa.ac.uk/index.php?option=com_ datatables\&Itemid=121\&task=show_category\&catdex $=3$.

Higher Education Statistics Agency (2005/6a). 'Resources of Higher Education Institutions, Cheltenham', http://www.hesa.ac.uk/index.php?option=com_ datatables\&Itemid $=121 \&$ task $=$ show_category\&catdex $=1$.

Higher Education Statistics Agency (2005/6b). 'Students in Higher Education Institutions, Cheltenham', http://www.hesa.ac.uk/index.php?option=com datatables\&Itemid=121\&task=show_category\&catdex $=3$.

Johnes, G. and Johnes, J. (forthcoming). 'Higher Education Institutions' Costs and Efficiency: Taking the Decomposition a Further Step', Studies in Higher Education, in press.

Johnes, J. (2004). 'Efficiency Measurement', in G. Johnes and J. Johnes (eds), The International Handbook on the Economics of Education, Cheltenham, Edward Elgar. 
Johnes, J. (2006). 'Data Envelopment Analysis and its Application to the Measurement of Efficiency in Higher Education', Economics of Education Review, Vol. 25, No. 3, pp. 273-288.

Ray, S. C. and Desli, E. (1997). 'Productivity Growth, Technical Progress and Efficiency Change in Industrialized Countries: Comment', American Economic Review, Vol. 87, No. 5, pp. 1033-1039.

Worthington, A. C. (2001). 'An Empirical Survey of Frontier Efficiency Measurement Techniques in Education', Education Economics, Vol. 9, No. 3, pp. 245-268.

Worthington, A. C. and Lee, B. L. (2007). 'Efficiency, Technology and Productivity Change in Australian Universities 1998-2003', Economics of Education Review, Vol. 27, No. 3, pp. 285-298. 